\title{
Antecedentes de la semiótica
}

\author{
Background of semiotics
}

DOI: $10.46932 / \mathrm{sfjdv2n2-143}$

Received in: March 1st, 2021

Accepted in: May 30th, 2021

\author{
Martha Judith Soto Flores \\ 1 Escuela Superior de Artes Visuales (ESAV). Tijuana, Baja California, México. \\ E-mail: soto@esav.edu.mx
}

\section{RESUMEN}

Recientemente, el estudio de la semiología ha cobrado progresivamente mayor presencia en la currícula de programas como artes visuales, plásticas, diseño gráfico, comunicación, lingüística, literatura, arquitectura y otros. Sin embargo, como disciplina, es difícil decir cuándo y cómo nace; su origen y su estado actual. Muchos autores atribuyen su origen al norteamericano Peirce y al suizo Saussure, cuando en realidad el término semiótica es mucho más antiguo y su fundación como disciplina es anterior o posterior a estos dos autores, dependiendo del criterio que se elija. Es un buen momento para hacer un repaso del origen histórico y desarrollo de la disciplina semiológica que se está tratando de consolidar como parte integral y útil de la currícula de todas estas profesiones.

Palabras clave: arte, diseño, semiología, semiótica.

\begin{abstract}
Recently, the study of semiology has progressively gained presence in the curricula of programs such as visual arts, fine arts, graphic design, communication sciences, linguistics, literature and others. Nevertheless, as a discipline, it is hard to say when and how it was born; its origin and current state. Many authors attribute its origins to the American Peirce and the Swiss Saussure, when in truth the term semiotics is much older and its inception as a discipline is either earlier or later to these two authors, depending on the chosen criteria. It is a good time to make a review of the historical origin and development of the semiologic discipline that is striving to consolidate as an integral and useful part of the curricula in all those professions.
\end{abstract}

Key words: Art, design, semiology, semiotic.

\section{PLANTEAMIENTO}

La semiótica se ha integrado en años recientes a la currícula universitaria como disciplina que estudia los signos; en programas como diseño, comunicación, artes, arquitectura, lingüística y filosofía entre otros. Universidades nacionales y extranjeras ofrecen maestrías en este tema; como es la Universidad Anáhuac, donde se implementó la Maestría en Semiótica en México o en la Universidad de Bogotá Jorge Tadeo Lozano en Colombia. Al final de los noventas, algunas universidades implementaron cursos y líneas de investigación sobre semiótica, como la Escuela Nacional de Lenguas, Lingüística y Traducción 
(UNAM) en su Posgrado de Lingüística. ${ }^{1}$ Este interés por entender el 'significado' ha llevado a investigadores y docentes a implementar estudios y programas sobre semiótica. La Escuela Superior de Artes Visuales ha desarrollado por 16 años teoría y metodología aplicadas a la comprensión del significado en artes y diseño, bajo el rubro semiología.

\title{
2 DESARROLLO
}

En su tesis para el grado de Doctor en Artes, el Dr. Jaime Jiménez Cuanalo expone los criterios de una larga serie de autores e identifica los puntos de acuerdo o principales características básicas que una práctica académica debe reunir para ser considerada una disciplina de estudio -científica o no: a) Objeto de estudio explícito y exclusivo, b) campo problemático general respecto de su objeto, c) método formalizado y d) integración teórica.

Desde la antigüedad el ser humano ha tenido la necesidad de darle un significado a las cosas, encontramos que en la grecia clásica en el diálogo de Crátilo de Platón (470-460 a.C.) menciona una discusión entre Sócrates, Cratilo y Hermógenes sobre el fenómeno significativo, refiriéndose a la relación entre los nombres y las cosas:

\begin{abstract}
Hermógenes.- Ve aquí, mi querido Sócrates, a Cratilo, que pretende que cada cosa tiene un nombre que le es naturalmente propio; que no es un nombre aquél de que se valen algunos, después de haberse puesto de acuerdo, para servirse de él [...] Respecto a mí, mi querido Sócrates, después de muchas discusiones con nuestro amigo y con muchos otros, no puedo creer que los nombres tengan otra propiedad que la que deben a la convención y consentimiento de los hombres. Tan pronto como alguno ha dado un nombre a una cosa, me parece que tal nombre es la palabra propia; y si, cesando de servirse de ella, la reemplaza con otra, el nuevo nombre no me parece menos propio que el primero. (Platón, 1984: pp. 249-250)
\end{abstract}

Sin embargo también encontramos otros autores griegos como Aristóteles (384-321) que tenía un interés por el tema de la significación, particularmente en cuanto al uso de algunos términos semiológicos. González Ochoa menciona que Aristóteles hacía la distinción del concepto como referente convencional del lenguaje.

[...] las palabras son símbolos o signos de las afecciones o impresiones del alma; las palabras escritas son signos de las palabras habladas. Al igual que la escritura tampoco el lenguaje es el mismo para todas las razas de hombres. Pero las afecciones mentales en sí mismas, de las que estas palabras son primariamente signos, son las mismas para toda la humanidad, como lo son también los objetos, de los que esas afecciones son representaciones, semejanza, imágenes o copias" (De la interpretación, 16a). (González, 1986: p. 25)

Aristóteles plantea que las palabras son símbolos de las experiencias mentales y las experiencias mentales son símbolos de las cosas.

\footnotetext{
${ }^{1}$ Escuela Nacional de Lenguas, Lingüística y traducción. UNAM. http://dla.cele.unam.mx/semiotica/indice.html
} 
Las palabras, aunque remiten a las cosas, son principalmente signos de las afecciones del alma, pues "las afecciones del alma son las mismas para todos los hombres". Por lo tanto, entre las cosas reales y los conceptos las relaciones son de similaridad, es decir, naturales, pero entre los signos y las cosas las relaciones son convencionales ya que entre ellos están los conceptos. Tenemos pues en Aristóteles, el germen de la estructura ternaria del signo, la cual reaparece a lo largo de la historia hasta llegar a nuestro siglo con los triángulos de Ullman y de Ogden y Richards; los tres componentes en Aristóteles son: los "símbolos" gráficos o fónicos, los "afectos del alma" y las "cosas". En términos de Aristóteles, tenemos primero el semainon, o sea el signo en sentido propio, pero como entidad física; el semainomenon, que es lo que se dice del signo, el sentido; y el pragma, el objeto al cual se refiere el signo, y que es un acontecimiento o una acción. (González, 1986: pp. 25-26)

En el período helenístico o periodo alejandrino (Alejandro Magno 323 a.C.) la escuela estoica decía que las palabras tienen su origen en la representación "[...] por lo tanto, son creadas por naturaleza y las categorías lingüísticas reproducían el pensar; por ende, las del ser mismo; distinguían tres factores en la situación semántica: el símbolo, como sonido material, el significado o la significación y la propia cosa externa." (León, 2014: p. 30)

El manejo del lenguaje es un tema importante en el pensamiento de San Agustín (354-430), ya que el signo es utilizado para crear mensajes.

[...] De magistro muestra una acendrada conciencia de la importancia de los signos para la vida humana. Y en el De doctrina christiana dice que las cosas se dividen en signos y significantes. [...] "es la cosa que, además de la especie [o imagen] que introduce en los sentidos, hace pasar al pensamiento de otra cosa distinta. ( Beuchot, 2012: pp. 19-20)

En el medievo Santo Tomás de Aquino (1224-1274) a lo largo de su obra podemos encontrar el manejo del signo lingüístico, abordando temas en general sobre el signo y sus aspectos. "Esto lo lleva a definir el signo así: "El signo es aquello por lo que alguien llega al conocimiento de otra cosa". ( Beuchot, 2012: pp. 35-36)

En 1690 John Locke publicó el ensayo sobre el entendimiento humano, donde se menciona el término semiótica, proponiendo la división del conocimiento humano en tres áreas ciencias:

[...] primero la física o filosofía natural, cuyo fin es la pura verdad especulativa "y todo lo que puede enriquecer a la mente humana en cualquier sentido"; en segundo lugar está la ética, que se ocupa de descubrir las reglas y medidas de las acciones humanas "que llevan a la felicidad"; y en tercer lugar la semiótica o doctrina de los signos, también llamada lógica. Su objetivo es el estudio de "la naturaleza de los signos que la mente usa para la comprensión de las cosas, o para comunicar su conocimiento a los demás” (Ibíd.: 1068). (González, 1986: p. 45)

Alexander Baumgarten, en su obra Aesthetica Scripsit ${ }^{2}$ publicado en 1750, menciona a la semiótica, como aquella parte de la estética que define "El pulcro conocimiento y disposición de los

\footnotetext{
${ }^{2}$ Él escribió la estética.
} 
signos." ; pero además, en uno de sus 'apéndices' hace uso tanto del término semiótica como -por primera vez hasta donde sabemos- del término semiología y procede a realizar un análisis de su objeto de estudio. Otros autores como Johann H. Lambert ${ }^{4}$ o Charles Morris ${ }^{5}$ han publicado obras donde se hace mención al estudio de la semiótica, pero Morris es quizá el primero en tener un correlacionar el término con el auténtico objeto de estudio semiológico, al presentar la semiótica como la ciencia de la semiosis.

A principios del siglo XX surgen dos autores a quienes se ha atribuido la fundación de la semiótica; uno, Charles Sanders Peirce (1839-1914), que retoma la propuesta de Locke de identificar la semiótica con la lógica, por lo que se le ha considerado uno de los fundadores del estudio de la semiótica contemporánea, y otro, el suizo Ferdinand de Saussure (1857-1913), quien no aborda en ningún sentido el estudio del tema, pero alrededor de 1910 usó la palabra semiología -introducida por Baumgarten casi dos siglos antes- para una posible ciencia que se dedicara al estudio de los signos en el seno de la vida social. A partir de este punto, ambos términos parecieron confundirse, como lo evidencia Pierre Guiraud. Roland Barthes al conocer las propuestas de Saussure referente al estudio de la semiología, asume que los elementos semiológicos se agrupan de la siguiente manera: "I. Lengua y habla; II. Significado y significante; III. Sintagma y sistema; IV. Denotación y connotación.” (Barthes,2009: p. 28) Para Barthes la semiología se encontraba en proceso de construcción, por lo cual asegura que no puede existir un método o un manual de análisis ya que consideraba que sería la ciencia de todo los sistemas de los signos. “[...] la semiología no podrá ser tratada didácticamente hasta que estos sistemas hayan sido reconstruidos empíricamente.”(Barthes,2009: p. 17)

\footnotetext{
¿Qué es, entonces, para mí, la semiología? Es una aventura, es decir, lo que me adviene (lo que me viene del significante).

Esta aventura (personal, pero no subjetiva, porque lo escenificado en ella es precisamente el desplazamiento del sujeto y no su expresión) (Barthes, 2009: p. 15)
}

Pierre Guiraud (1971) tomando de referencia los estudios semiológicos de Saussure propone lo siguiente: "La semiología es la ciencia que estudia los sistemas de signos: lenguas, códigos, señalizaciones, etc. De acuerdo con esta definición, la lengua sería una parte de la semiótica. [...] "el estudio de los sistemas de signos no lingüísticos" (Guiraud, 1972: p. 7)

Umberto Eco (1974) en el tratado de semiótica general define el objeto de estudio de la semiótica, tomando en cuenta a Peirce, Saussure, Morris y otros autores seguidores de las propuestas de Peirce y Saussure. "Una teoría semiótica general debe considerarse 'potente' en la medida en que consigna

\footnotetext{
3 signis pulcre cogitatorum et dispositorum.

${ }^{4} 1764$ en su Neues Organon, Johann H. Lambert dedicó un apartado a la Semiotik oder Lehre von der Bezeichnung der Gedanken und dinge.

${ }^{5}$ Charles Morris Foundations of the Theory of Signs. University of Chicago, 1938.
} 
proporcionar una definición formal apropiada para cada clase de función semiótica ya sea ésta codificada, codificada o codificante." (Eco, 2012: p. 19) Eco pretende aclarar el objeto de investigación de la semiótica. "Este estudio reviste la forma de una TEORÍA SEMIÓTICA GENERAL capaz de explicar toda clase de casos de FUNCIÓN SEMIÓTICA desde el punto de vista de SISTEMAS subyacentes relacionados por uno o más CÓDIGOS.” (Eco, 2005: p. 17).

Jiménez Cuanalo al analizar las propuestas de estudio de la semiótica de otros autores se da cuenta que la implementación de esta disciplina carece tanto de un modelo teórico general como de un protocolo del método científico y una correcta identificación de su objeto y problema; por lo quea al ser implementado en los programas de estudio en licenciatura y posgrado, sus métodos son poco acertados y sus resultados tienden a quedarse en el campo de la especulación sin alcanzar certeza científica. Jiménez toma de referencia los estudios de neurociencias, estudios de la biología de la visión y de la teoría biológica-evolutiva del comportamiento, e implementa el primer método aplicado al arte y diseño, facilitando al creativo el realizar análisis y dictámenes sobre la semiosis en el diseño, sea publicitario, arquitectónico, industrial o en las artes.

Por lo que Jiménez comenta que, para que la semiología o semiótica prospere y de resultados útiles, es indispensable que se formalice como una disciplina científica de estudio. Para esto hay que expresar de manera correcta su objeto, su problema de estudio, método y su teoría general de partida. En este sentido propone que el objeto de estudio explícito y exclusivo de la semiótica debe de ser el fenómeno de la semiosis - de la significación-como proceso, con todos los elementos que conllevan o intervienen en la semiosis en estricto sentido pero además en la semiosis en general y no en ninguno de sus aspectos particulares como la lógica, la lingüística, la sintomatología, etc.

Jiménez Cuanalo difiere de otros autores que le han adjudicado a la semiología o semiótica como objeto de estudio ciertos tipos de semiosis parciales: la comunicación humana o, más específicamente, la lingüística; los sistemas conceptuales formales, como la lógica, etc. En cuanto al problema de una disciplina científica, este debe ser general, respecto de su objeto; en este caso se formula con la pregunta fundamental ¿qué es la semiosis? Que a su vez implica las preguntas ¿cómo funciona la semiosis? y ¿qué efectos produce la semiosis? Estas tres preguntas medulares: ¿qué es, cómo funciona y qué efectos producen? constituyen y deberían ser consideradas el campo problemático de cualquier disciplina de estudio.

En cuanto al método, se propone el método científico; a través de un protocolo que incluya el requerimiento de que todos los datos sean observables -verificables por terceros independientes-, que todos los argumentos constituyan cadenas lógicas ininterrumpidas, que el lenguaje que se use sea técnico, claro, objetivo y concreto. Que la investigación tenga un flujo lógico, donde se identifique correctamente 
el objeto y problema de cada investigación particular, se haga un análisis funcional de sus partes para planificar la investigación por objetivos específicos, se apliquen las técnicas científicamente aceptables de observación y razonamiento para obtener los datos, se sintetice la información en un modelo teórico y, finalmente, se interpreten los resultados. Para que esta disciplina inicie como una ciencia se necesitará una teoría general de la significación y esta deberá explicar ¿qué es la significación? ¿cómo funciona? y ¿qué efectos produce? en general. Por lo cual se propone que la significación es un proceso de asociación de configuraciones actualmente percibidas con configuraciones pre-registradas, en base a una 'función' que puede ser natural, artificial o cultural (artificial convencionalizada). En principio, la semiosis nace con los sistemas biológicos, en función de la toma de decisiones que correlacionan el medio ambiente con la supervivencia del ser vivo y evoluciona con los seres humanos, a través del arte, hasta los sistemas enteramente arbitrarios y convencionales del lenguaje stricto senso.

La implementación del estudio de la semiótica en los planes de estudio en las escuelas y universidades de diseño en México inicia a partir de los setentas; los contenidos de la materia en semiótica en las escuelas mexicanas de diseño son de preocuparse, ya que los profesores e investigadores no tienen claro cuál es la aplicación de esta en el diseño y tienden a implementarla como materia histórica. Al revisar el estado del conocimiento referente al estudio de la semiótica o semiología, podemos darnos cuenta que algunos autores coinciden con el objeto de estudio y otros mencionan que debería ser una disciplina científica. Jiménez propone en su libro Curso de semiología para artistas y diseñadores una aproximación metodológica al estudio de la semiología, donde el creativo puede predecir el efecto significativo que su propuesta de diseño tendrá para el usuario, lo cual a su vez, permite predecir o manipular la respuesta o conducta del receptor del diseño. Uno de los problemas frecuentes en el diseño es comprender cuál es la función y significación de su proyecto.

\section{CONCLUSIONES}

El estudiar la semiología en las escuela de diseño o arquitectura es una herramienta útil, ya que el diseño no sólo obtenemos elementos materiales sino también -y de manera más importante-cumple una función de significación. Algunos arquitectos contemporáneos, en los años sesentas, generaron los primeros estudios de la relación de la arquitectura y la semiótica. Al diseñar una silla no solamente es necesario tener conocimientos ergonómicos y constructivos, sino de la función sociocultural que el usuario espera que cumpla la silla; es decir, debemos saber si es un trono para un rey que deberá de representar el status o jerarquía del usuario, o una mecedora que debe representar la tradición y el confort. Por lo que es importante aclarar que la semiótica es una ciencia que, como cualquier otra, tiene como 
misión producir modelos teóricos que se puedan aplicar tecnológicamente para tomar mejores decisiones sobre su objeto, en este caso la significación.

Por más de una década, la Escuela Superior de Artes Visuales ha venido aplicando el modelo teórico de la semiología propuesta por Jiménez (2017), implementando tecnologías que dan ventaja a los arquitectos de interiores y artistas visuales que allí se forman, haciendo más fácil y eficiente el proceso de alcanzar dominio sobre los efectos significativos que sus propuestas artísticas y de diseño causan sobre el público. Por supuesto, esto se puede hacer sin la ciencia semiológica, sólo que al precio de un largo proceso de ensayo y, sobre todo, de errores acumulados; por lo que, como en otros dominios del quehacer humano, la ciencia - en este caso la semiología- nos da una alternativa mucho más práctica, eficaz y que permite una evolución más allá de lo que se puede lograr sin ella. 


\section{BIBLIOGRAFÍA}

ABBAGNANO, Incola. (1987). Diccionario de Filosofía. México: FCE.

BARTHES, Roland. (2009). La aventura semiológica. España: Paidós.

BAUMGARTEN, Alexander Gottlieb. (1750). Aesthetica Scripsit. Alemania.

(1988). Esthétique. Traducción de Jean-Yves Pranchère. Francia: L’Herne.

BEUCHOT, Mauricio. (2012). La semiótica. México: FCE.

ECO, Umberto. (2012). Tratado de semiótica General. México: Debols!llo.

GONZÁLEZ OCHOA, César. (1986). Imagen y sentido. Elementos para una semiótica de los mensajes visuales. México: UNAM.

GUIRAUD, Pierre. (2011). La semiología. México: Siglo XXI.

JIMÉNEZ CUANALO, Jaime. (2017). Curso de semiología para artistas y diseñadores. USA: Zona Límite.

(2020) Tratado General de Semiología. USA: Zona Límite. PLATÓN. (1984). Diálogos. México: Porrúa.

VENTURI, Robert. (1980). Complejidad y Contradicción en la Arquitectura. Barcelona: Gustavo Gili. 